\title{
Cap polyposis
}

INSERM

\section{Source}

INSERM. (1999). Orphanet: an online rare disease and orphan drug data base. Cap polyposis. ORPHA:160148

Cap polyposis (CP) is a rare colorectal disease characterized by multiple inflammatory polyps that predominantly affect the rectosigmoid area and that manifests primarily as rectal bleeding with abnormal transit, constipation and diarrhea. 